\title{
Opening the Microcirculation with Ketanserin I.V. Improves Peripheral Temperature: An Observational Cohort Study
}

\author{
Peter HJ van der Voort ${ }^{1,2}$, Rob J Bosman ${ }^{1}$, Eric JF Franssen ${ }^{3}$, and Saskia Rijkenberg ${ }^{1}$ \\ ${ }^{1}$ Department of intensive care, OLVG hospital Amsterdam, The Netherlands \\ ${ }^{2}$ TIAS School for Business and Society, Tilburg University, Tilburg, The Netherlands \\ ${ }^{3}$ Department of clinical pharmacology, OLVG hospital Amsterdam, The Netherlands
}

"Corresponding author: Peter HJ van der Voort, Department of Intensive Citation: van der Voort PH, Bosman RJ, Franssen EJ, Rijkenberg S (2017) Care, Medical Centre Leeuwarden, PO Box 888, 8901 BR, Leeuwarden, The Opening the Microcirculation with Ketanserin I.V. Improves Peripheral Netherlands, E-mail: phjvdvoort@chello.nl Temperature: An Observational Cohort Study. Enliven: J Anesthesiol Crit

Received Date: $13^{\text {th }}$ February 2017

Accepted Date: $22^{\text {nd }}$ February 2017

Published Date: $27^{\text {th }}$ February 2017 Care Med 4(1): 003.

Copyright: @ 2017 Dr. Peter HJ van der Voort. This is an Open Access article published and distributed under the terms of the Creative Commons Attribution License, which permits unrestricted use, distribution and reproduction in any medium, provided the original author and source are credited.

\begin{abstract}
Objectives

Skin mottling and an increased delta temperature (deltaT) between core and peripheral sides as measurements of microcirculatory dysfunction are associated with increased mortality in intensive care patients. We studied the effect on deltaT of ketanserin, a 5-HT2 receptor-blocking agent.
\end{abstract}

\section{Methods}

A retrospective analysis was performed of all intensive care patients that received ketanserin by continuous infusion. Over four to eight consecutive hours the change in deltaT (forefoot) was determined. To exclude lead-time bias we compared with a three-hour period before the start of ketanserin.

\section{Results}

1875 consecutive patients received a mean total dose of 225 (SD 110) $\mu \mathrm{g} / \mathrm{kg} / \mathrm{min}$ ketanserini.v. The peripheral temperature rose mean $2.6^{\circ}$ Cover eight hours and delta $\mathrm{T}$ declined mean $2.4^{\circ} \mathrm{C}$. A repeated measures analysis showed a significant rise in peripheral temperature. Comparing three hours before with three hours after start of ketanserin, all other parameters did not significantly change.

\section{Conclusion}

The microcirculation measured as peripheral temperature of critically ill patients, significantly improved with a continuous infusion of ketanserin. This increase is not associated with hypotension or the need of vasoconstrictors.

Keywords: Microcirculation; Peripheral temperature; Ketanserin; Critically ill; Intensive care; Mottling; Delta-temperature

\section{Introduction}

Critically ill patients with cold acra or skin mottling and the relation with shock have been recognized for many years [1]. Skin mottling is a presentation of vasoconstriction and appears to be an independent predictor for mortality $[2,3]$ in critically ill patients. Cold acra with an increased difference between core temperature and peripheral temperature, delta temperature (deltaT), has been studied as a representative of vasoconstriction [4]. DeltaT is associated with lactate levels and outcome in intensive care patients [4-6] and with cardiac index in post-cardiac surgery patients [7]. It is presumed that patients with vasoconstriction in the skin simultaneously experience vasoconstriction elsewhere, which can lead to organ dysfunction and, ultimately, mortality [8]. This presumed vasoconstriction at organ sites is hard to measure but for the oral mucosa the side-stream dark-field (SDF) microscopy is available $[9,10]$. Skin perfusion measured by peripheral temperature, SDF and capillary refill time are all measurements of vasoconstriction but often show disparity [11]. On the other hand, all are related with outcome in the critical care setting $[2,3,12,13]$. Although a relation between peripheral vasoconstriction 
and outcome exists, it is unknown whether active treatment of peripheral vasoconstriction will result in a better outcome. It is also unknown which medication can be used to resolve peripheral vasoconstriction. It was shown previously that nitroglycerin $[14,15]$ and dobutamine [16] improves the microcirculation measured with SDF microscopy. Scarce data exist about ketanserinin ICU patients $[17,18]$. Ketanserin is a serotonin type 2-receptor blocker (5-HT2) [19,20]. In normal endothelium the 5-HT1 effects (vasodilation) are the most prominent [21]. In endothelium that is damaged, which is the case in sepsis, the 5HT2 effects (vasoconstriction) surpass the 5-HT1 effects $[22,23]$. Blocking the 5-HT2 receptor with ketanserin can attenuate this pathological vasoconstriction. In addition, ketanserin has favourable $\alpha_{1}$-adrenergic blocking properties in the endothelium (vasodilation) that may further reverse the pathological vasoconstriction [23]. In these ways ketanserin can reduce vasoconstriction and can improve the microcirculation. As a consequence, the enhanced blood flow in the skin will increase the peripheral temperature and decrease deltaT.

\section{Material and Methods}

Aim

This study aims to determine whether the suggested clinical effect on peripheral temperature of a continuous infusion of ketanserin occurs in clinical practice. If so, it can be a starting point for new microcirculatory studies.

\section{Ethical Statement}

The local medical ethical committee (MEC OLVG) approved the study and waived the requirement for written informed consent because of its observational design according to Dutch and European regulations (registered with no. WO16092). This manuscript adheres to the applicable Equator guidelines. No data of this study were published previously in any form.

\section{Design}

The study is designed to address an increase in peripheral temperature in order to obtain insight in the capacity of ketanserin in reducing delta temperature between core and peripheral temperature. Outcome data such as mortality or length of stay were considered less relevant because of the large number of other variables that determine these outcomes. A retrospective cohort design was chosen because of the large availability of data were a prospective design would not be able to include this amount of patients.

\section{Patients and Setting}

All critically ill patients admitted to our ICU between January 2011 and March 2016 were evaluated. We selected all patients from the ICU database who were registered users of ketanserin. Included for analysis were patients who were treated with a continuous intravenous infusion of ketanserin. Excluded were patients who had missing peripheral temperature measurement at the time of ketanserin start or who had missing peripheral temperature measurements more than half of the eight-hour study period (more than four hours).

The study was performed in a 20-bed mixed ICU in a teaching hospital with medical, surgical and cardiac surgery patients. This ICU has a 24/7 attendance of intensivists and residents.

\section{Measurements}

All data were prospectively measured and stored in the ICU database (MetaVision $^{\circledR}$, Tel Aviv, Israel). In this ICU it is a routine procedure to measure peripheral temperature on the forefoot continuously and the attending nurse validates this temperature every hour. The protocol for the study defined a priori a time period of eight hours as this is a clinically relevant time frame in which treatment goals can be reached. To study whether changes in the outcome measurement within this time frame could be explained by lead-time bias, also data from three hours before start of ketanserin treatment were extracted. Thus, the peripheral temperature is extracted from the database, starting from three hours before the ketanserin infusion was begun (T-3) and consecutive peripheral temperature with an interval of one hour until eight hours (T-3 till T8) after start. In addition, we extracted the core temperature (blood, rectal, nasopharynx or tympanic) data together with fluid balance and other vasoactive medications.

\section{General Management}

Patients are continuously monitored and receive bedside titrated individualized treatment at the physician level. Circulatory management is protocolled aiming at a mean arterial pressure of $60 \mathrm{mmHg}$ using fluids, noradrenaline and, in previous years, dopamine to the discretion of the attending physicians. Enoximone is used when the attending physician deemed necessary. Ketanserin can be prescribed when apparent vasoconstriction is present but exact reasons to prescribe ketanserin were not recorded routinely. The attending physician, dependent on the clinical situation, chose the dose.

\section{Statistical Analysis}

Data is presented as mean with standard deviation (SD) in case of normal distribution and median with interquartile range (IQR) in all other situations.

Data are analysed as a time series of eight hours after start of ketanserin or as two subsequent episodes (three hours before compared to 3 hours after start of ketanserin. The difference between two time episodes is analysed by the related samples Wilcoxon signed rank test. The consecutive temperatures in the time series were analysed using a repeated measures ANOVA with a Greenhouse-Geisser correction. The post hoc tests used Bonferroni correction. The significance level was set at $5 \%$ for two-sided tests.

\section{Results}

From the database 2041 patients were identified who were treated with a continuous intravenous infusion of ketanserin. However, 2 patients appeared not to have received ketanserin at all and were excluded. Peripheral temperature measurement at $\mathrm{T} 0$ was missing in 118 patients and they were excluded for analysis. In 46 patients more than four peripheral temperature measurements were missing between $\mathrm{T} 0$ and $\mathrm{T} 8$ and they were excluded too. The final analysis included 1875 patients. Table 1 and 2 shows the baseline characteristics of these patients. The average administered ketanserin dose was 225 (SD 110) $\mu \mathrm{g} / \mathrm{kg}$ over eight hours. 
Tabe 1: Baseline Characteristics

\begin{tabular}{|l|l|}
\hline Age* (yrs) & $66.3(13)$ \\
\hline Male (\%) & 61.8 \\
\hline APACHE IV predicted mortality* & $0.32[0.12-0.59]$ \\
\hline Mechanically ventilated** $(\%)$ & 84.3 \\
\hline MAP T0 $(\mathrm{mmHg})$ & $74.8(17)$ \\
\hline Heart Rate $\mathrm{T} 0(\mathrm{bpm})$ & $95(20)$ \\
\hline Peripheral temperature $\mathrm{T} 0{ }^{\circ} \mathrm{C}$ & $29.9(3.2)$ \\
\hline Central temperature $\mathrm{T}^{\circ}{ }^{\circ} \mathrm{C}$ & $36.5(1.5)$ \\
\hline
\end{tabular}

Data are presented as mean with standard deviation (SD) or median with interquartile range [IQR]

APACHE IV: Acute Physiology and Chronic Health Evaluation; MAP: mean arterial pressure

* Recorded in the first 24 hours of ICU stay

** At any time during ICU stay

Table 2: The Distribution of Admission Diagnoses of included Patients

\begin{tabular}{|l|l|l|}
\hline \multicolumn{3}{|c|}{ Admission Diagnoses } \\
\hline & Frequency & Percent \\
\hline $\begin{array}{l}\text { Coronary artery bypass grafting and/ } \\
\text { or valve surgery }\end{array}$ & 226 & 12 \\
\hline Other cardiac surgery & 34 & 0.2 \\
\hline Aortic surgery & 160 & 8.5 \\
\hline Other vascular surgery & 79 & 4.2 \\
\hline Thoracic surgery, lung or other & 12 & 0.6 \\
\hline Cardiac arrest & 169 & 9.0 \\
\hline Cardiogenic shock/ & & \\
\hline Congestive heart failure & 115 & 6.1 \\
\hline Cardiovascular other & 35 & 1.9 \\
\hline Sepsis & 359 & 19 \\
\hline Pneumonia & 166 & 8.9 \\
\hline Respiratory failure & 117 & 6.2 \\
\hline GI bleeding +/- surgery & 54 & 2.9 \\
\hline GI surgery & 157 & 8.4 \\
\hline Pancreatitis & 10 & 0.5 \\
\hline GI medical & 17 & 0.9 \\
\hline Genitourinary surgery & 7 & 0.4 \\
\hline Coma/CVA/neurological & 34 & 1.8 \\
\hline Hepatic failure & 18 & 1.0 \\
\hline Renal failure, acute & 20 & 1.1 \\
\hline Haematological & 12 & 0.6 \\
\hline Haemorrhage /hypovolemia & 30 & 1.6 \\
\hline Orthopaedic & 7 & 0.4 \\
\hline Trauma & 14 & 0.7 \\
\hline Metabolic/hyperthermia/hypothermia & 13 & 0.7 \\
\hline Gynaecology & 7 & 0.4 \\
\hline Surgery, other & & 0.1 \\
\hline Other & 0.0 \\
\hline Total & 100,0 \\
\hline
\end{tabular}

$3 \quad$ Enliven Archive | www.enlivenarchive.org

\section{T-3 till T0 versus $T 0$ till $T+3$ hours}

The median rise in peripheral temperature (Table 3 ) from $\mathrm{T}-3$ to $\mathrm{T} 0$ is $0.2^{\circ} \mathrm{C}$ (IQR $-0.6-1.2^{\circ} \mathrm{C}$ ) and from $\mathrm{T} 0$ to $\mathrm{T} 3$ is $0.9^{\circ} \mathrm{C}\left(\mathrm{IQR} 0.0-2.3^{\circ} \mathrm{C}\right) ; \mathrm{p}=0.001$. In the same episode the changes in mean arterial pressure, enoximone dose, nitroglycerin dose, noradrenalin dose and dopamine dose were not significantly different as is shown in table 3 . The volume of infusion was significantly greater between during $\mathrm{T}-3$ till $\mathrm{T} 0$ compared to $\mathrm{T} 0$ till $\mathrm{T}+3$ hours (434 vs. $597 \mathrm{ml})$.

\section{$T=0$ till $T=8$ hours}

The mean peripheral temperature three hours before the start of ketanserin and subsequent one-hour interval time points are summarized in table 4 . A graduate increase of $2.6^{\circ} \mathrm{C}$ in peripheral temperature from $\mathrm{T} 0$ to $\mathrm{T} 8$ is shown and a decrease in mean $\Delta \mathrm{T}$ between central and peripheral temperature of $2.4^{\circ} \mathrm{C}$. The repeated measurements ANOVA with Greenhouse Geisser correction determined that the peripheral temperature significantly increased between time points $(\mathrm{F}(2.395,4021)=642.9, \mathrm{p}<0.001)$. All pairwise comparisons were significant at a $\mathrm{p}<0.001$ level with Bonferroni correction. The estimated marginal means of the peripheral temperature from start of ketanserin till eight hours later is shown in figure 1. Figure 2 shows the mean deltaT over time.

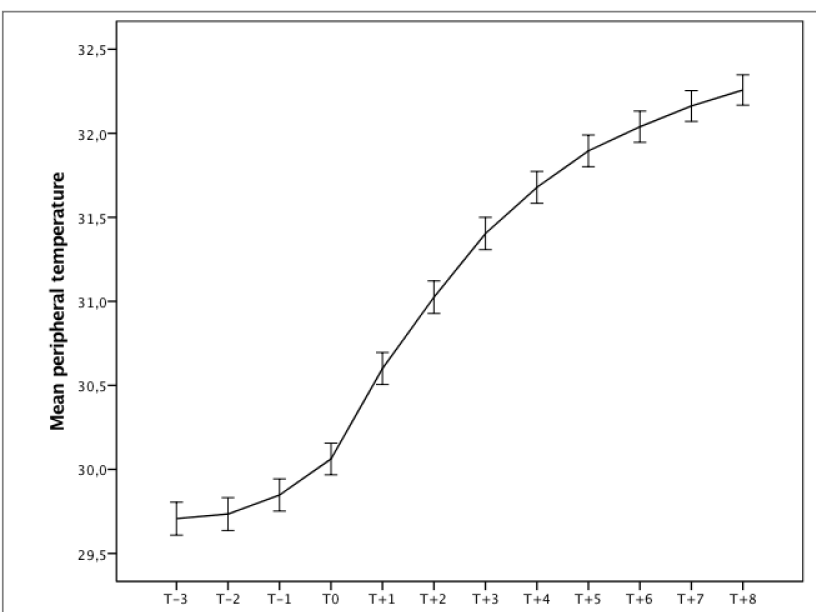

Figure 1: The $\mathrm{x}$-axis shows the time per hour from three hours before start of ketanserin infusion (T-3), the y-axis shows the estimated marginal means of the peripheral temperature in ${ }^{\circ} \mathrm{C}$ derived from the repeated measures ANOVA. The error bars are the SE of mean.

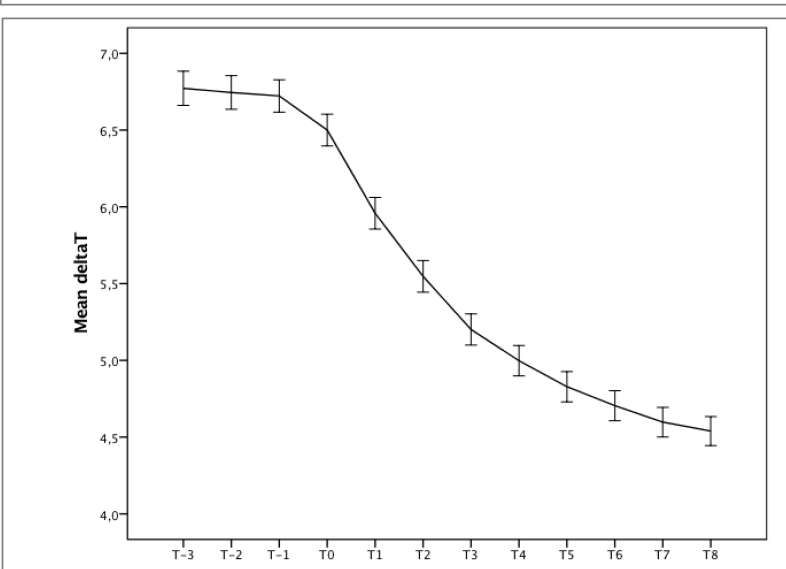

Figure 2: The $\mathrm{x}$-axis shows the time per hour from three hours before start of ketanserin infusion (T-3), the y-axis shows the means of the difference between central and peripheral temperature (deltaT) in ${ }^{\circ} \mathrm{C}$. The error bars are the SE of mean. 
Table 3: Characteristics of the Circulation and Medication before and after Ketanserin Start

\begin{tabular}{|l|l|l|l|}
\hline & $\boldsymbol{\Delta}(\mathbf{T}-\mathbf{3}-\mathbf{T 0})$ & $\boldsymbol{\Delta}(\mathbf{T 0}-\mathbf{T}+\mathbf{3})$ & $\boldsymbol{\Delta}(\mathbf{T}+\mathbf{8}-\mathbf{T 0})$ \\
\hline Peripheral temperature $\left({ }^{\circ} \mathbf{C}\right)$ & $0.2{ }^{\circ} \mathrm{C}[-0.6-1.2]$ & $0.9[0.0 \pm 2.3]^{*}$ & $2.2[0.5-4.7]$ \\
\hline Mean arterial pressure $(\mathbf{m m H g})$ & $-1.0[-10.0 \pm 9.0]$ & $-2.0[-10 \pm 5]^{\#}$ & $-1.0[-8 \pm 7]$ \\
\hline Noradrenalin $\mathbf{( \mu g} / \mathbf{k g} / \mathbf{m i n})$ & $0.0[-0.01 \pm 0.02]$ & $0.0[0.00-0.02]^{\#}$ & $0.0[-0.02 \pm 0.02]$ \\
\hline Dopamine $(\boldsymbol{\mu g} / \mathbf{k g} / \mathbf{m i n})$ & $0.0[0.00-0.00]$ & $0.0[0.00-0.00]^{\#}$ & $0.0[0.0-1.4]$ \\
\hline Enoximone $\boldsymbol{\mu g} / \mathbf{k g} / \mathbf{m i n}$ & $0.0[0.00-0.00]$ & $0.0[0.00-0.00]^{\#}$ & $0.0[0.0-0.0]$ \\
\hline Nitroglycerin $\boldsymbol{\mu g} / \mathbf{k g} / \mathbf{m i n}$ & $0.0[0.00-0.00]$ & $0.0[0.00-0.00]^{\#}$ & $0.0[0.0-0.0]$ \\
\hline Ketanserin $\boldsymbol{\mu g} / \mathbf{k g} / \mathbf{m i n}$ & - & $0.0[0.00-0.00]$ & $0.0[0.00-0.00]$ \\
\hline Fluid balance $\mathbf{( m l )}$ & $597[109-1291]$ & $434[52-919]^{*}$ & $1395[469-2529]$ \\
\hline
\end{tabular}

${ }^{*} \mathrm{p}<0.001$ compared to $\Delta(\mathrm{T}-3-\mathrm{T} 0)$; \#not significant compared to $\Delta(\mathrm{T}-3-\mathrm{T} 0)$

Data are given as a change over three hours before $(\Delta(\mathrm{T} 0-\mathrm{T}-3))$, three hours after $(\Delta(\mathrm{T}+3-\mathrm{T} 0))$ and eight hours $(\Delta(\mathrm{T}+8-\mathrm{T} 0))$ after start of ketanserin. Data are presented as median and interquartile range [IQR]; P value obtained by using Wilcoxon signed rank test for paired samples.

Table 4: Mean peripheral temperature displayed from three hours before start of ketanserin (pT-3) till eight hours after start (pT+8) and delta temperature between central and peripheral temperature $(\Delta T)$ in the same episode.

\begin{tabular}{|l|l|l|l|}
\hline & Mean (SD) & & Mean (SD) \\
\hline $\mathbf{p T}-\mathbf{3}(\mathbf{N}=\mathbf{1 2 7 3})$ & $29.8(3.3)$ & $\Delta \mathrm{T}-3$ & $6.7(3.2)$ \\
\hline $\mathbf{p T}-\mathbf{2}(\mathbf{N}=\mathbf{1 6 3 6})$ & $29.4(3.3)$ & $\Delta \mathrm{T}-2$ & $7.0(3.3)$ \\
\hline $\mathbf{p T}-\mathbf{1}(\mathbf{N}=\mathbf{1 8 4 5})$ & $29.5(3.2)$ & $\Delta \mathrm{T}-1$ & $7.0(3.3)$ \\
\hline $\mathbf{p T 0}(\mathbf{N}=\mathbf{1 8 7 5 )}$ & $29.9(3.2)$ & $\Delta \mathrm{T} 0$ & $6.6(3.2)$ \\
\hline $\mathbf{p T + 1}(\mathbf{N}=\mathbf{1 8 5 6})$ & $30.5(3.2)$ & $\Delta \mathrm{T}+1$ & $5.9(3.1)$ \\
\hline $\mathbf{p T}+\mathbf{2}(\mathbf{N}=\mathbf{1 8 5 1})$ & $31.0(3.2)$ & $\Delta \mathrm{T}+2$ & $5.5(3.1)$ \\
\hline $\mathbf{p T}+\mathbf{3}(\mathbf{N}=\mathbf{1 8 5 8})$ & $31.5(3.2)$ & $\Delta \mathrm{T}+3$ & $5.1(3.0)$ \\
\hline $\mathbf{p T + 4} \mathbf{( N = 1 8 4 8 )}$ & $31.8(3.2)$ & $\Delta \mathrm{T}+4$ & $4.8(3.0)$ \\
\hline $\mathbf{p T}+\mathbf{5}(\mathbf{N}=\mathbf{1 8 3 2})$ & $32.0(3.1)$ & $\Delta \mathrm{T}+5$ & $4.6(2.9)$ \\
\hline $\mathbf{p T}+\mathbf{6} \mathbf{( N = 1 8 1 6 )}$ & $32.2(3.1)$ & $\Delta \mathrm{T}+6$ & $4.5(2.9)$ \\
\hline $\mathbf{p T}+\mathbf{7} \mathbf{N}=\mathbf{1 7 8 3})$ & $32.3(3.0)$ & $\Delta \mathrm{T}+7$ & $4.4(2.8)$ \\
\hline $\mathbf{p T}+\mathbf{8}(\mathbf{N}=\mathbf{1 7 5 5})$ & $32.4(3.0)$ & & $4.3(2.7)$ \\
\hline
\end{tabular}

SD: standard deviation

\section{Discussion}

This study aimed to investigate whether a continuous intravenous infusion a three-hour episode before and a three-hour episode after the start of of ketanserin is able to improve peripheral temperature. It is shown that over ketanserin. After this three-hour period the increase in peripheral temperature a period of eight hours peripheral temperature rose with a mean of $2.6^{\circ} \mathrm{C}$ is still seen but less vigorous. This demonstrates that ketanserin can be used and delta temperature with core measurement decreased with $2.4^{\circ} \mathrm{C}$. Though to increase the peripheral temperature by enhancing the peripheral perfusion vasodilatation must have occurred, there is no increase in the infusion of without blood pressure fall or the need of additional vasoconstrictors. The fluids when comparing the first three hours before with three hours after start clinical importance of this finding lies in the relation between a compromised of ketanserin. This is in accordance with previous experimental study where peripheral circulation and the enhanced mortality risk associated with this splanchnic and other perfusion increased without increasing aortic flow [24]. situation. Studies that describe a high lactate or a high peripheral to central Over the complete 8 hours period almost $1400 \mathrm{ml}$ of fluid is retained but temperature difference are associated with a higher mortality [4,6,25]. On the no drop in blood pressure or rise in vasopressor use is seen. Apparently, the other hand, it has not been shown yet that improvement of this temperature skin perfusion in our patients improved, which is not only apparent from a $2.6^{\circ} \mathrm{C}$ rise in peripheral temperature but also from a $2.4^{\circ} \mathrm{C}$ decrease in deltaT between core and peripheral temperature (Table 4). The dose of other vasoactive medication did not significantly change over the same episode after the start of ketanserin. Thus, other vaso-active medication than ketanserin cannot explain the increase in peripheral temperature. We choose to compare gap reduces mortality or improves any other outcome measurement. The only suggestion for a benefit in the literature is shown by the improved outcome in patients with active lactate decreasing treatment, including vasodilators like nitroglycerin and ketanserin [25]. In this study the active treatment group used nitroglycerin and ketanserin more often than the control group. In addition, no positive effects were observed with ketanserin in preeclampsia [26]. 
Our study has several strengths and limitation. This is the first study that directly measures the clinical effect of ketanserin on peripheral temperature in critically ill patients. As such, ketanserin can be seen as the only medication that has been studied so far and that has shown to be able to improve the peripheral temperature and deltaT. This should be seen in the context that a large delta $\mathrm{T}$ is associated with increased mortality. The major limitation of this study is that it is a retrospective analysis in a single centre cohort study. On the other hand, the large number of patients and the consistent increase in peripheral temperature is convincing. With this knowledge, ketanserin can now be studied in prospective trials in patients with peripheral vasoconstriction in an attempt to reduce the excessive mortality of patients with vasoconstriction. Furthermore, ketanserin needs to be compared to other vasodilators. In this retrospective study it is not feasible to obtain effects of ketanserin on outcome measurements such as mortality. A prospective study is needed with this focus. Included in such a study should be other effects of ketanserin such as a reduction of inflammatory cytokines, which may be beneficial too [27].

In conclusion, we have shown that ketanserin is able to improve peripheral temperature in critically ill patients without increasing the need for fluids or vasopressors. Whether this effect is of clinical importance should be studied in future studies.

\section{Financial Disclosures and Funding: none}

Conflicts of Interests: The Author(s) declare(s) that there is no conflict of interest.

\section{References}

1) Joly HR, Weil MH (1969) Temperature of the great toe as an indication of the severity of shock. Circulation 39:131-138.

2) Coudroy R, Jamet A, Frat JP, Veinstein A, Chatellier D, et al. (2015) Incidence and impact of skin mottling over the knee and its duration on outcome in critically ill patients. Intensive Care Med 41:452-459.

3) Ait-Oufella H, Lemoinne S, Boelle PY, Galbois A, Baudel JL, et al. (2011) Mottling score predicts survival in septic shock. Intensive Care Med 37: 801-807.

4) Lima A, Jansen TC, van Bommel J, Ince C, Bakker J (2009) The prognostic value of the subjective assessment of peripheral perfusion in critically ill patients. CritCare Med 37:934-938.

5) Kaplan LJ, McPartland K, Santora TA, Trooskin SZ (2001) Start with subjective assessment of skin temperature to identify hypoperfusion in intensive care unit patients. J Trauma 50: 620-628.

6) Bourcier S, Pichereau C, Boelle PY, Nemlaghi S, Dubée V, et al. (2016) Toe-to-room temperature gradient correlates with tissue perfusion and predicts outcome in selected critically ill patients with severe infections. Ann Intensive Care 6:63.

7) Bailey JM, Levy JH, Kopel MA, Tobia V, Grabenkort WR (1990) Relationship between clinical evaluation of peripheral perfusion and global hemodynamics in adults after cardiac after cardiac surgery. Crit Care Med 18: 1353-1356.

8) Brunauer A, Koköfer A, Bataar O, Gradwohl-Matis I, Dankl D, et al. (2016) Changes in peripheral perfusion relate to visceral organ perfusion in early septic shock: a pilot study. J Crit Care 35:105-109.
9) Groner W, Winkelman JW, Harris AG, Ince C, Bouma GJ, et al. (1999) Orthogonal polarization spectral imaging: a new method for study of the microcirculation. Nat Med 5:1209-1212.

10) Boerma EC, Mathura KR, van der Voort PHJ, Spronk PE, Ince $C$ (2005) Quantifying bedside-derived imaging of microcirculatory abnormalities in septic patients: a prospective validation study. Crit Care 9: R601-R606.

11) Boerma EC, Kuiper MA, Kingma WP, Egbers PH, Gerritsen RT, et al. (2008) Disparity between skin perfusion and sublingual microcirculatory alterations in severe sepsis and septic shock: a prospective observational study. Intensive Care Med 34:1294-1298.

12) Ait-Oufella H, Bige N, Boelle PY, Pichereau C, Alves M, et al. (2014) Capillary refill time exploration during septic shock. Intensive Care Med 40: 958-964.

13) Sakr Y, Dubois MJ, De Backer D, Creteur J, Vincent JL (2004) Persistent microcirculatory alterations are associated with organ failure and death in patients with septic shock. Crit Care Med 32:1825-1831.

14) Spronk PE, Ince C, Gardien MJ, Mathura KR, Oudemans-van Straaten HM, et al. (2002) Nitroglycerin in septic shock after intravascular volume resuscitation. Lancet 360: 1395-1396.

15) Lima A, van Genderen ME, van Bommel J, Klijn E, Jansem T, et al. (2014) Nitroglycerin reverts clinical manifestations of poor peripheral perfusion in patients with circulatory shock. Crit Care 18:R126.

16) De Backer D, Creteur J, Dubois MJ, Sakr Y, Koch M, et al. (2006) The effects of dobutamine on microcirculatory alterations in patients with septic shock are independent of its systemic effects. Crit Care Med 34: 403-408.

17) Elbers PW, Ozdemir A, van Iterson $M$, van Dongen EP, Ince $C$ (2009) Microcirculatory imaging in cardiac anesthesia: ketanserin reduces blood pressure but not perfused capillary density. J CardiothoracVascAnesth23:95-101.

18) Vellinga NA, Veenstra G, Scorcella C, Koopmans M, van Roon EN, et al. (2015) Effects of ketanserin on microcirculatory alterations in septic shock: an open-label pilot study. J Crit Care 30:1156-1162.

19) Van Nueten JM, Janssen PAJ, van Beek J, Xhonneux R, Verbeuren TJ, et al. (1981) Vascular effects of ketanserin (R41468), a novel antagonist of 5-HT2 serotonergic receptors. J PharmacolExpTher 218:217-230.

20) Persson B, Heykants J, Hedner T (1991) Clinical pharmacokinetics of ketanserin. ClinPharmacokinet 20:263-279.

21) Dabiré H, Cherqui C, Safar M, Schmitt H (1990) Haemodynamic aspects and serotonin. ClinPhysiolBiochem 8:56-63.

22) Van der Starre PJ, Reneman RS (1994) The role of serotonin blockers in cardiac anesthesia. J CardiothoracVascAnesth 8:455-462.

23) Reimann IW, Frolich JC (1983) Mechanisms of antihypertensive action of ketanserin in man. Br Med J 287:381-383.

24) Arvidsson S, Falk A, Haglind E, Haglund U (1983) The role of 5-hydroxytryptamine in the feline response to intravenous infusion of live E. coli. Br J Pharmacol 79:711-718.

25) Jansen TC, van Bommel J, Schoonderbeek FJ, SleeswijkVisser SJ, van der Klooster JM, et al. (2010) Early lactate-guided therapy in intensive care unit patients. Am J RespirCrit Care Med 182:752-761. 
26) Bijvank SW, Visser W, Duvekot JJ, Steegers EA, Edens MA, et al. (2015) Ketanserin versus dihydralazine for the treatment of severe hypertension in early-onset preeclampsia: a double blind randomized controlled trial. Eur J ObstetGynecolReprodBiol 189:106-111.
27) Liu C, Zhang GF, Song SW, Cai GJ, Liu WH, et al. (2011) Effects of ketanserin on endotoxic shock and baroreflex function in rodents. J Infect Dis 204:1605-1612.

Submit your manuscript at http://enlivenarchive.org/submit-manuscript.php New initiative of Enliven Archive

Apart from providing HTML, PDF versions; we also provide video version and deposit the videos in about 15 freely accessible social network sites that promote videos which in turn will aid in rapid circulation of articles published with us. 